\title{
Development of a competency framework for quality improvement in family medicine: A qualitative study
}

Citation for published version (APA):

Czabanowska, K., Klemenc-Ketis, Z., Potter, A., Rochfort, A., Tomasik, T., Csiszar, J., \& Van den

Bussche, P. (2012). Development of a competency framework for quality improvement in family medicine: A qualitative study. Journal of Continuing Education in the Health Professions, 32(3), 174-180.

https://doi.org/10.1002/chp.21142

Document status and date:

Published: 01/01/2012

DOI:

10.1002/chp.21142

Document Version:

Publisher's PDF, also known as Version of record

Document license:

Taverne

Please check the document version of this publication:

- A submitted manuscript is the version of the article upon submission and before peer-review. There can be important differences between the submitted version and the official published version of record.

People interested in the research are advised to contact the author for the final version of the publication, or visit the DOI to the publisher's website.

- The final author version and the galley proof are versions of the publication after peer review.

- The final published version features the final layout of the paper including the volume, issue and page numbers.

Link to publication

\footnotetext{
General rights rights.

- You may freely distribute the URL identifying the publication in the public portal. please follow below link for the End User Agreement:

www.umlib.nl/taverne-license

Take down policy

If you believe that this document breaches copyright please contact us at:

repository@maastrichtuniversity.nl

providing details and we will investigate your claim.
}

Copyright and moral rights for the publications made accessible in the public portal are retained by the authors and/or other copyright owners and it is a condition of accessing publications that users recognise and abide by the legal requirements associated with these

- Users may download and print one copy of any publication from the public portal for the purpose of private study or research.

- You may not further distribute the material or use it for any profit-making activity or commercial gain

If the publication is distributed under the terms of Article $25 \mathrm{fa}$ of the Dutch Copyright Act, indicated by the "Taverne" license above, 


\title{
Development of a Competency Framework for Quality Improvement in Family Medicine: A Qualitative Study
}

\author{
Katarzyna Czabanowska, MA, PhD; Zalika Klemenc-Ketis, MD, PhD; Amanda Potter, MS; \\ Andrée Rochfort, MB, BCh, MICGP; TOMASz TOMASIK, MD, PhD; Judit Csiszar, MD, MScEd, MBA; \\ Piet Van den Bussche, MD
}

\begin{abstract}
Objective: The aim of this study was to develop a comprehensive framework of quality improvement competencies for use in continuing professional development (CPD) and continuing medical education (CME) for European general practice/family medicine physicians (GPs/FDs).
\end{abstract}

\begin{abstract}
Methods: The study was carried out in three phases: literature review, consensus development panels, and Delphi technique. An initial competencies framework was developed from an extensive literature review focusing on literature in English from 2000 to 2011 and addressing quality improvement competencies for general practitioners in continuous education programs. Two rounds of reviews by consensus development panels were undertaken to evaluate and make changes to the initial draft competency framework. Then two rounds of Delphi surveys were carried out in an effort to reach consensus on the domains and competencies included in the framework. Our goal was for $90 \%$ to $100 \%$ consensus. Both surveys were presented through SurveyMonkey, an online survey service, and sent by e-mail to members of the European Association for Quality and Patient Safety in General Practice/Family Medicine (EQuiP), a network organization of Wonca Europe.
\end{abstract}

Results: The Quality Improvement Competencies Framework was developed. It consists of a list of 35 competencies organized into the following domains: Patient Care \& Safety, Effectiveness \& Efficiency, Equity \& Ethical Practice, Methods \& Tools, Leadership \& Management, and Continuing Professional Education.

Conclusion: We believe that the framework can serve as a useful tool for identifying gaps in knowledge and skills and guiding the development of CPD and CME curricula for GPs/FDs not only in Europe but also in other regions, including the United States and Canada, on the assumption that many of the core tasks of quality improvement would be relevant across multiple contexts.

Key Words: quality improvement, competencies, family medicine, qualitative study, continuing professional development

Disclosures: The authors report none.

Dr. Czabanowska: Assistant Professor, Maastricht University, Faculty of Health, Medicine and Life Sciences, CAPHRI School of Public Health and Primary Care, Department of International Health; Dr. Klemenc-Ketis: Assistant Professor, Department of Family Medicine, Medical School, University of Maribor, Maribor, Slovenia and Department of Family Medicine, Medical School, University of Ljubljana; Ms. Potter: Research Assistant, Maastricht University, Faculty of Health, Medicine and Life Sciences, CAPHRI School of Public Health and Primary Care, Department of International Health; Dr. Rochfort: Director, Health in Practice Programme, Irish College of General Practitioners, Honorary Secretary European Association for Quality and Patient Safety in General Practice/Family Medicine (EQuiP); Dr. Tomasik: Senior Lecturer, Department of Family Medicine, Chair of Internal Medicine and Gerontology, Jagiellonian University Medical College; Dr. Csiszar: Senior Technical Advisor, Project HOPE Czech Republic, Global Health Department Prague; Dr. Van den Bussche: Department of Primary Care and General Practice, University of Ghent.

\section{Introduction}

Modern medicine recognizes that the outcomes of clinical care depend not only on how doctors put their clinical knowledge and training into practice, but also their skills such as dealing with the continuous flow of new information and medical evidence, and effectively managing available resources. ${ }^{1}$ There is also growing evidence that quality of

Correspondence: Katarzyna Czabanowska, P.O. Box 616, 6200 MD Maastricht; e-mail: kasia.czabanowska@maastrichtuniversity.nl

(c) 2012 The Alliance for Continuing Education in the Health Professions, the Society for Academic Continuing Medical Education, and the Council on Continuing Medical Education, Association for Hospital Medical Education. - Published online in Wiley Online Library (wileyonlinelibrary.com) DOI: $10.1002 / \mathrm{chp} .21142$ 
care is, to a large extent, determined by the organization or system in which patient care is delivered. ${ }^{2}$ The organizational context of care delivery may facilitate or inhibit efforts to improve practice. ${ }^{3}$ This means that family doctors of today need to be able to reflect on the organizational systems in which they deliver care and, as needed, effectively participate in changing those systems to improve the quality of that care. ${ }^{4}$ At the same time, doctors face increasing demands, as a consequence of the complex expectations of patients, ${ }^{5}$ developments in science and technology, and limitations within health care systems. ${ }^{6}$

This perspective on the determinants of the quality of care has important consequences for medical education programs. Among other things, it means that doctors need training in the competencies required for quality improvement (QI), which we define as "the combined and unceasing efforts of healthcare professionals, patients and their families, researchers, payers, planners and educators to make changes that will lead to better patient outcomes, better system performance and better professional development."7 Attempts to address the need for physician training in QI have, however, been uneven. A recent European study on teaching $\mathrm{QI}^{8}$ showed many differences in QI curricula between European countries and different organizations within individual countries. We believe this is attributable, in part, to the absence of a widely accepted model describing the competencies required of physicians if they are to fully participate in quality improvement.

Competency models can enhance educational initiatives in multiple ways. A competency-based curriculum focuses attention on the outcomes of the instruction and how it improves the learner and the learners' work rather than focusing purely on acquiring knowledge (as is often the case with traditional instruction). A QI competency framework can provide the basis for a self-assessment tool to help individual GPs/FPs identify their training needs. Just as quality improvement requires health care professionals to be clear about outcomes, ${ }^{9}$ general practitioners also need to have clear and focused guidelines for choosing their educational goals. A competency framework can also provide an organising structure to guide the development and evaluation of educational programs. ${ }^{10}$ Teachers and trainers who develop and provide continuing professional development (CPD) programs could, for example, use the framework to identify and target important QI competencies. There are several organizations that are interested in QI curricula for physicians or other clinicians, not only in Europe but also in North America. These include the American Medical Group Association (AMGA), American Academy of Family Physicians, and Accreditation Association for Ambulatory Health Care. We believe that a QI competency framework can be a valuable resource to these organizations as well in the process of constructing their own curricula.
Despite the potential of a QI competency model to enhance doctor education, our review of the literature found that no comprehensive models currently exist. We did find several typologies incorporating elements of QI in health care that have been developed in the past 20 years. Some of them have served as a basis for developing QI curricula at different levels of education. For example, a model from the United States ${ }^{11}$ identified 7 major aspects of quality of care-patient safety, effectiveness, patient centeredness, timeliness, efficiency, and equity - and these were incorporated into medical curricula for QI. The Canadian educational framework for medical students (CanMeds), which was developed primarily for specialty residents and then adopted for undergraduate students, includes 6 categories, none of which addresses QI directly: medical expert, communicator, collaborator, manager, health advocate, scholar, and professional. ${ }^{12}$ However, some mention of QI competencies is found in the competencies comprising these categories. For example, "Participate in systemic quality process evaluation and improvement, such as patient safety initiatives" is included under "manager." In the field of continuous medical education (CME), Greiner and co-authors ${ }^{12}$ defined 5 core competencies for health professionals: providing patient-centered care, working in interprofessional teams, employing evidence-based practice, applying quality improvement, and utilizing informatics. While including more information about QI competencies than CanMeds, Greiner et al fail to recognize competencies related to ethics and professionalism. The Bellagio model $^{13}$ put forward 9 essential features for delivery of effective chronic care: leadership, public trust (accountability and transparency), population-oriented management, vertical and horizontal integration, networking of professionals, infrastructure, payment mix, standardized measurement, and an active program of change. ${ }^{13}$ This model provides a comprehensive competency model for chronic care of patients and cannot serve as a comprehensive competency framework for QI in general. Finally, there are the competencies for practicing physicians developed by the American Board of Medical Specialties (ABMS): patient care, medical knowledge, interpersonal and communication skills, professionalism, system-based practice, and practice-based learning and improvement. ${ }^{14}$ The same competencies were also adopted for undergraduate students. ${ }^{15}$ These frameworks form the basis of training for the majority of medical learners in the Western world ${ }^{16}$ but cannot serve as comprehensive QI models as they do not address several areas that are essential to QI, such as research tools, leadership, and management.

In the absence of an existing model, we aimed to develop a comprehensive list of QI competencies for use in planning and evaluating CME programs for European general practitioners (GPs) and family doctors (FDs). We sought to achieve this outcome by developing consensus among a group of QI experts on the key competencies required for 
family doctors in Europe to assure high-quality care and to develop QI processes. ${ }^{17,18}$ Although our focus was primary care physicians in Europe, we anticipated that this list would also be useful to CME planners in other regions, including the United States and Canada, on the assumption that many of the core tasks of QI would be relevant across multiple contexts and health care systems.

\section{Methods}

A descriptive study was carried out in three consecutive phases: literature review, consensus development, and implementation of a Delphi process. Each subsequent phase was informed by and built upon the preceding phase.

\section{Literature Review}

To create an initial list of QI competencies, four databases-PubMed, Cochrane Library, EMBASE, and Google Scholar-were searched as part of an extensive literature review. The search was limited to publications published from 2000 to 2011 that were written in English and included an abstract. The search strategy employed the following key words: continuing/continuous medical education; continuing/continuous professional development; quality improvement competencies; quality improvement; quality improvement curriculum; teaching quality improvement; general practitioner/family practice/general physician; general practitioners/family physicians and quality improvement competencies; and quality improvement and medical education. In addition, relevant quality improvement and general practice association Web sites were reviewed for descriptions of QI competencies and related literature.

Following the initial search, two of the authors ( $\mathrm{KC}$ and AP) independently screened the titles and abstracts. They found 362 relevant citations. The citations were further narrowed by excluding articles that related to undergraduate education, residency programs, and non-general practice specialities. A final total of 35 citations was included.

We then reviewed the full text of the studies for possible competencies relevant to both family medicine and quality improvement. For the purposes of our study, competency was defined as a synthesis of knowledge, skills, and attitudes that enables family physicians/general practitioners to deliver high quality care. ${ }^{19,20}$ A preliminary list of competencies was compiled and duplicate concepts merged by the same reviewers ( $\mathrm{KC}$ and $\mathrm{AP}$ ). Any disagreements among reviewers were resolved through discussion. The competencies were then organized into domains synthesized from the sources or based on existing frameworks for general practice and quality improvement. ${ }^{10,11,13,17}$

\section{Consensus Development Panels}

Two rounds of consensus development panels were undertaken to evaluate and make changes to the initial draft competency framework. Consensus development panels are a qualitative method for obtaining agreement in areas of uncertainty or where there is a lack of definitive information. ${ }^{21,22}$ Furthermore, consensus development panels help bring professionals together to directly comment and develop tools and techniques. ${ }^{22}$

The first panel for the QI framework took place during a European Association for Quality in General Practice (EQuiP) Invitational Conference in 2011. EQuiP is one of the Wonca Europe network organizations comprising 43 representatives officially designated by national colleges/associations of family doctors from European countries. The vast majority of representatives are practicing family physicians/general practitioners with a special interest and experience in quality improvement activities in primary health care. They are also involved in teaching QI at different educational levels (undergraduate, postgraduate, and CME). The authors offered a workshop entitled "Competence-Based Education in Quality Improvement for General Practitioners/Family Doctors in Europe" at this conference. Fifteen EQuiP members chose to participate, representing 6 countries (Ireland, Austria, Slovenia, Hungary, Belgium, and Poland). Seven of the 15 (47.0\%) were men. During this activity, participants were given a presentation defining the scope of the project and relevant definitions such as quality improvement, competence, and family practice. They were then directed to individually review the draft list of domains and their associated competencies. They were asked to mark each competency according to its relevance for inclusion in the model, suggest possible changes in the competency statement, and suggest possible changes in the appropriate domain. After the reviewers individually evaluated the items, they convened in 3 groups to continue work on the list. The results from these groups were pooled after the conference to create an amended framework.

A second consensus panel review was conducted via a questionnaire as a means of reaching agreement on the changes introduced after the first round. The amended competencies were e-mailed to the 15 first-round review participants. Each expert was asked to review the list and to invite a colleague/expert in family medicine and quality improvement from their country to also review the list. The new questionnaire asked respondents to evaluate the competencies and the domains used to organize the competencies. Responses were received from 6 of the first-round reviewers and 6 of their colleagues, for a total of 12 reviewers. These participants were from Ireland, Austria, Slovenia, Poland, Belgium, and Hungary. Based on our analysis of the survey results, the 6 domains created during the conference were 
retained, with minor edits. Individual competencies were edited and reorganized based on the majority recommendation of the experts.

As an additional quality check, we recruited an expert who is not a member of EQuiP, a general practice expert from Maastricht University Medical Centre, Department of Integrated Care. She evaluated the framework and discussed her observations in a one-to-one meeting, recommending small edits to the competency list and the addition of "Develop and monitor individualized health care plan with the patient" under the Patient Care \& Safety domain.

\section{Delphi Survey}

Having refined the framework, a 2-round Delphi survey was conducted to validate and establish consensus on a final framework. The Delphi method helped us to create an environment that allowed for partial anonymity, iterations of the survey, and controlled feedback. ${ }^{23}$ A traditional Delphi process begins with a survey gathering opinions from participants followed by 2 or more rounds to reach consensus. ${ }^{24}$ The number of survey rounds, size of expert pool, and degree of consensus required are defined by the researcher, but typically 2 or more rounds of surveying must be conducted. ${ }^{25}$ Since we had already completed the consensus development panels, we chose to have 2 rounds of Delphi surveys in an effort to finalize and obtain a high level of consensus on the competency framework. A minimum of 10 respondents was sought in each round. Respondents were members of EQuiP (some of whom had the opportunity to contribute to the previous qualitative expert panel review). It is suggested that 10 to 15 Delphi participants are sufficient if their background is homogeneous. ${ }^{22}$ We decided that competencies receiving scores of greater than $90 \%$ would be considered to have achieved consensus.

Both rounds of Delphi surveys were presented through SurveyMonkey, an online survey service, and sent by e-mail to 33 active EQuiP members inviting them to participate in the study and complete the survey. The first Delphi survey sought a simple "yes/no/with changes" response on the inclusion of each competency domain area. Participants were then asked to respond "yes/no/with changes" on the inclusion and grouping of each competency. Altogether, the first-round questionnaire consisted of 44 questions. In addition, space was provided to add other competencies that respondents considered suitable for family physician practice. The respondents could also submit arguments for or against the proposed competencies (by supporting their opinion with literature references). Following 2 reminders, 13 responses were received. Items with less than $90 \%$ consensus were edited to bring them closer in line with the observations of the respondents. The second Delphi survey contained 3 questions and sought a simple "yes/no" response approving the edits made in the previous round and the framework as a whole.

This study involved no patients or human material. Participants in the consensus panel and Delphi survey were informed of the purpose of this study and were given the opportunity to self-select their participation. It was conducted in compliance with the Helsinki Declaration.

\section{Results}

Based on our literature review, 55 competencies were identified and organized into 5 domains: Patient Care \& Safety, Ethics, Research \& Evaluation, Leadership \& Management, and Education \& Continuing Education. As a result of the first phase of the consensus development process, the list was narrowed to 37 competencies. A new domain was added (Effectiveness \& Efficiency), increasing the total to 6, and 2 domains were reformulated to be more comprehensive: Ethics was changed into Equity \& Ethical Practice and Research \& Evaluation was amended to Methods \& Tools. Based on the results of the workshop and responses to the questionnaire that followed, the list was reduced to 35 competencies organized into 6 domains.

In the first Delphi round, 13 participants contributed. They reached $100 \%$ consensus on all but one competency (which obtained 90\% consensus): "Respect patients' personal rights." Participants reached 100\% consensus on 5 of the 6 domain areas. One individual commented that Leadership \& Management could be a subsection of Effectiveness \& Efficiency.

After revision, the framework was presented for a second and final Delphi round. We reached $100 \%$ consensus on the domain areas with 1 objection to the final framework (TABLE 1). Under the Equity \& Ethical Practice domain, 1 respondent still disagreed with inclusion of "Respect patients' personal rights" as a separate competence and suggested merging it with "Respect patient autonomy," which might be considered to represent a similar concept. Since there was only 1 objection and 12 approvals, resulting in $92 \%$ agreement, we did not make the change. As we anticipated, 2 rounds yielded a high level of consensus, and no further Delphi rounds were conducted. Since during the second round the respondents proposed no new competencies, we concluded that saturation and consensus had been achieved. A circular structure for displaying the domains was adopted to emphasize the importance of integrating all areas of competency into a family practice (FIGURE 1 ).

\section{Discussion}

The framework that emerged from this process is a comprehensive and integrated tool embracing not only specific competencies related to patient care provided in a health care 
Czabanowska et al.

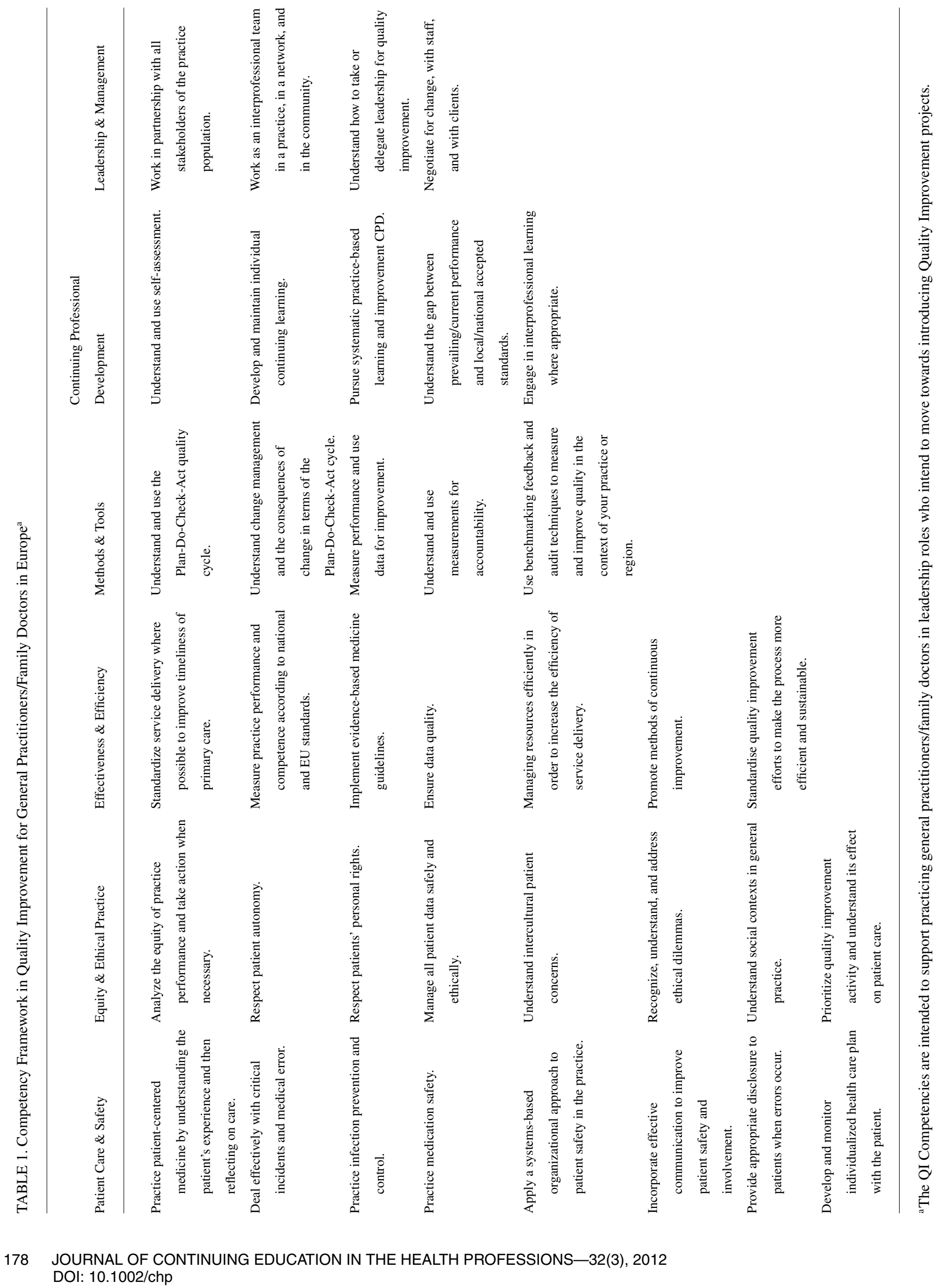




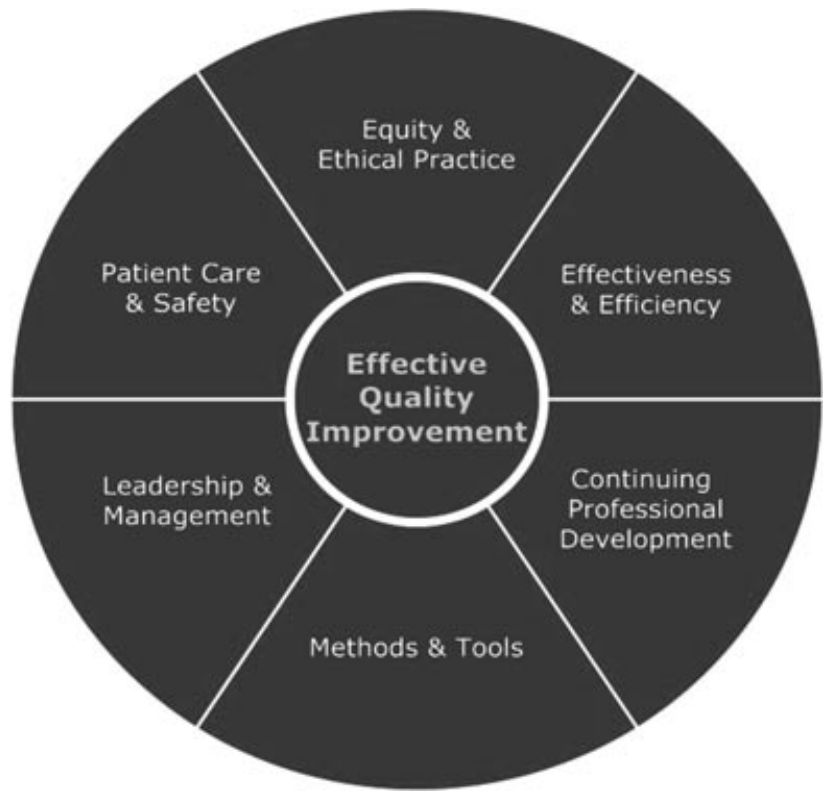

FIGURE 1. Competency Framework in Quality Improvement for Family Doctors in Europe

system, but also a range of cross-cutting, interdisciplinary, and social-interpersonal competencies such as negotiating for change, interprofessional teamwork, and social networking. This framework describes a role for GPs/FDs that is focused not only on clinical care of patients but also on organizational, ethical, and patient safety issues. The QI competencies identified show that GPs/FDs need to be able to adopt multiple roles when managing their patients and adapt to the requirements of the patient-centered medical care. This is consistent with the key features of family medicine: holistic approach, comprehensive approach, person-centered care, and community approach. ${ }^{23}$

This study produced a framework that is simultaneously more comprehensive and more focused than its predecessors. Prior studies of QI competencies needed by GPs/FDs to meet the challenges of increasingly complex modern medical practice addressed more limited and specific areas such as ethics ${ }^{26}$ or research tools and instruments. ${ }^{27-29}$ Our model covers the full range of QI competencies needed by FDs. In addition, the domains of our model were developed based on current frameworks for planning QI activities and educational programs. Combining the pivotal areas from multiple models into 6 domains allowed a new organization of the key competencies needed for general practitioners and the exclusion of extraneous competencies more suited to administrators, managers, or other more specific specialities.

Ours is a transdisciplinary framework that can be used to inform efforts to help practitioners respond effectively to the complex medical care environment in which they work. As the gatekeepers to other specialists and frequent negotiators of health management for patients with chronic illnesses, GPs/FDs require a holistic view of quality improvement and their place in the medical system. ${ }^{30}$ GPs/FDs are often the first and most frequently visited physicians, particularly in Europe. Therefore, systemic improvements must start with them. By actively incorporating quality improvement into their practices, family doctors can improve the systems in which patient care is delivered. ${ }^{2}$

Although qualitative approaches like consensus-building panels and the Delphi technique are very useful in identifying key competences, these approaches preclude firm conclusions and have limited representativeness. ${ }^{31}$ It should be noted that some researchers regard Delphi and other consensus-building techniques as methods of "last resort," as they rely on the opinions of a group rather than direct scientific evidence. ${ }^{32}$ Moreover, consensus building based on EQuiP participants may bias or restrict the guidelines to particular regions or types of general practice/family medicine. There is also the risk that in our desire to obtain consensus, we may not give enough attention to the dissenting voice. Despite these limitations, we believe our QI competency framework will prove to be a useful tool in the evaluation and assessment of educational needs related to QI.

Going forward, the authors intend to continue refining and validating the framework. Also planned is development of an online self-assessment tool that will be accessible to European family physicians/general practitioners. The tool will include all competences and domains from this study and will collect data about physicians' self-perceived competences. These data will be helpful for examining the criterion, content and construct validity of the developed list of competencies. ${ }^{32-34}$ The tool will also be accessible for GP teachers of QI and policy makers to bring other perspectives into the study and stimulate discussion about educational needs.

Our study shows that quality improvement activities in general practitioners/family doctors' practices constitute a complex and multidimensional aspect of clinical practice. The QI competency framework provides an important resource for GPs/FDs, teachers, and researchers. Application and evaluation of the framework are the next steps in our ongoing efforts to identify competency gaps in QI and formulate comprehensive and effective CPD curricula for general practice/family medicine.

\section{Acknowledgment}

This study was supported by the European Commission Lifelong Learning Program in the framework of the Leonardo da Vinci Project "Innovative lifelong learning of European General Physicians in Quality Improvement supported by information technology" (InGPinQI):No. 2010-1-PL1-LEO0511473. This publication reflects the views only of the authors, 


\section{Lessons for Practice}

\section{- Several frameworks for quality improvement in health care have been developed in the past 20 years but they do not comprehen- sively and specifically cover primary care.}

- This comprehensive competency framework for QI in general practice can serve as a useful tool in identifying gaps in knowledge and shaping CPD curricula for GPs/FDs.

and the Commission cannot be held responsible for any use that may be made of the information contained herein. We would like to thank InGPinQI project partners, EQuiP members, and Dr. Inge Duimel for their time and effort to help develop the Quality Improvement Competencies Framework by reviewing and giving feedback at consecutive stages of the research process.

\section{References}

1. Dawda P, Jenkins R, Varnam R. Quality Improvement in General Practice. London, England: The King's Fund; 2010.

2. Goodwin N, Dixon A, Poole T, et al. Improving the Quality of Care in General Practice. London, England: The King's Fund; 2011.

3. Leach DC. Changing education to improve patient care. Qual Health Care. 2001;10:ii54-ii58.

4. Legido-Quigley H, McKee M, Nolte E, et al. Assuring the Quality of Health Care in the European Union. Copenhagen, Denmark: World Health Organization; 2008.

5. Pink J, Jacobson L, Pritchard M. The 21st century GP: physician and priest? Br J Gen Pract. 2007;57(543):840-842.

6. Plsek PE, Greenhalgh T. Complexity science: the challenge of complexity in health care. BMJ. 2001;323(7313):625-628.

7. Batalden PB, Davidoff F. What is "quality improvement" and how can it transform healthcare? Qual Saf Health Care. 2007;16:2-3.

8. Klemenc-Ketis Z, VandenBussche P, Kersnik J, Emaus C. Teaching Quality in Family Medicine: Preliminary Results of a European CrossSectional Study [Internet]. Denmark: EQuiP. [updated: 2011; cited October 4, 2011]. Available at: http://www.equip.ch/files/55/10._zalika _klemenc_ketis_teaching_quality_in_family_medicine_preliminary_results _of_a_european_cross_sectional_study.pdf

9. Pruitt SD, Epping-Jordan JE. Preparing the 21st century global healthcare workforce. BMJ. 2005;330:637.

10. Frank JR, ed. The CanMEDS 2005 Physician Competency Framework. Ottawa, Ontario: Royal College of Physicians and Surgeons of Canada; 2005.

11. Institute of Medicine. Crossing the Quality Chasm: A New Health System for the 21st Century. Washington, DC: National Academies Press; 2001.

12. Greiner AC, Knebel E, eds. Health Professions Education: A Bridge to Quality. Washington, DC: Institute of Medicine; 2003.

13. Schlettes S, Frolich A, Marti T. The Bellagio Model: PopulationOriented Primary Care. Paper presented at the International Forum on Quality and Safety in Health Care, Berlin; 2009.
14. Maintenance of Certification Competencies and Criteria [Internet] USA: American Board of Medical Specialties. [updated 1999; cited October 4, 2011]. Available at: http://www.abms.org/Maintenance_of _Certification/MOC_competencies.aspx

15. Accreditation Council on Graduate Medical Education. General Competences for Residents. Chicago, IL: Accreditation Council on Graduate Medical Education; 2007.

16. Frank JR, Snell LS, Cate OT, et al. Competency-based medical education: theory to practice. Med Teach. 2010;32:638645.

17. Committee on Planning a Continuing Health Care Professional Education, Institute Board on Health Care Services. Redesigning Continuing Education in the Health Professions. Washington, DC: Institute of Medicine; 2010.

18. Continuing Professional Development in Primary Health Care [Internet]. Denmark: EURACT, EQuiP. [updated 2002; cited October 4, 2011]. Available at: http://equip2.dudal.com/files/4/policy_document _cme_equip_euract.pdf

19. Lawrence K, Allen T, Brailovsky C, et al. Defining competency-based evaluation objectives in family medicine: key-feature approach. Can Fam Physician. 2011;57(10):e373-380.

20. Tomasik T, Windak A, Domagala A, et al. An evaluation of family physicians' educational needs and experiences in health promotion and disease prevention in Poland and Lithuania-a qualitative study. BMC Fam Pract. 2011;25(12):13.

21. Green J, Thorogood N. Qualitative Methods for Health Research. 2nd ed. London, England: Sage; 2004.

22. Bowling A. Research Methods in Health: Investigating Health and Health Services. 2nd ed. Maidenhead, PA: Open University Press; 2003.

23. Evans P, ed. The European Definition of General Practice/Family Medicine. Leuven, Belgium: EURACT; 2005.

24. Jones J, Hunter D. Using the Delphi and nominal group technique in health service research. In: Pope C, Mays N, eds. Qualitative Research in Health Care. Bristol, England: BMJ Books; 2000.

25. Hasson F, Keeney S, McKenna H. Research guidelines for the Delphi survey technique. J Adv Nurs. 2000;32:1008-1015.

26. Tapp L, Edwards A, Elwyn G, et al. Quality improvement in general practice: enabling general practitioners to judge ethical dilemmas. $J$ Med Ethics. 2010;36:184-188.

27. Hoye S, Straand J, Brekke M. How do general practitioners keep up-to-date on pharmacology. Tidsskriftfor den NorskeLaegeforening. 2008;128(23):2692-2695.

28. Brouwer HJ, Bindels PJE, Weert HC. Data quality improvement in general practice. FamPract. 2006;23(5):529-536.

29. Varkey P, Gupta P, Bennet KE. An innovative method to assess negotiation skills necessary for quality improvement. Am J Med Qual. 2008;23(5):350-355.

30. Heyrman J, ed. The EURACT Educational Agenda. European Academy on Teachers in General Practice. Leuven, Belgium: EURACT; 2005.

31. Green LW, Kreuter MW. Health Promotion Planning: An Educational and Environmental Approach. 2nd ed. Mountain View, CA: Mayfield; 1991.

32. DeVon HA, Block ME, Moyle-Wright P, et al. A psychometric toolbox for testing validity and reliability. J Nurs Scholarsh. 2007;39(2):155164.

33. Frost MH, Reeve BB, Liepa AM, Stauffer JW, Hays RD. Mayo/FDA Patient-Reported Outcomes Consensus Meeting Group. What is sufficient evidence for the reliability and validity of patient-reported outcome measures? Value Health. 2007 Nov-Dec;10 Suppl 2:S94S105.

34. Brzeziński J. Metodologia badań psychologicznych. Warsaw, Poland: Wydawnictwo Naukowe PWN; 1999. 